\title{
Body Composition and Proportionality of Base and Top in Acrobatic Gymnastics of Young Portuguese Athletes: Short Report
}

\author{
David Paulo Ramalheira Catela ${ }^{1 *}$, Mafalda Nogueira Serôdio ${ }^{2}$ and Ana Paula de Lemos Teixeira e Seabra ${ }^{1}$ \\ ${ }^{1}$ Quality of Life Research Centre (CIEQV) and Research Centre of the Polytechnique Institute of Santarém (UIIPS), Santarem, \\ Portugal
}

${ }^{2}$ Sports Higher School of Rio Maior, Polytechnique Institute of Santarém, Portugal

\begin{abstract}
In acrobatic gymnastics there are specific morphological functional differences between bases (B) and tops (T). Previous studies show that $\mathrm{T}$ are significantly less tall, lighter and with less fat mass; and, that the competitive level influences these differences. In this study, weight, height, experience and competitive level was collected, and weight index (WI), lean body mass index (LBMI), body mass index (BMI), and percentiles 5 and 95 were estimated for 64 athletes (11.73 \pm 2.76 years of age, $148.77 \pm 16.56 \mathrm{~cm}$ in height, $40.49 \pm 12.59 \mathrm{~kg}$ in weight, $\mathrm{BMI}=17.79 \pm 2.47, \mathrm{WI}=98.87 \pm 2.66,4.64 \pm 2.91$ years of experience, $24 \mathrm{~T}, 7$ boys). The results revealed: i) no significant differences between genders; ii) a significant difference between $\mathrm{T}$ and $\mathrm{B}$ in height and weight, with a proportion from $\mathrm{T}$ to $\mathrm{B}$ of $87.44 \%$ and $62.83 \%$, respectively; iii) a significant difference between $\mathrm{T}$ and B in BMI and LBMI, with a proportion from $\mathrm{T}$ to $\mathrm{B}$ of $63.52 \%$ and $117.74 \%$, respectively; iv) no significant difference between $\mathrm{T}$ and $\mathrm{B}$ in WI; v) a significant inverse association between competition level and WI; vi) a LBMI of B and T significantly higher than the normal median value. Therefore, in young acrobatic gymnasts there is already a higher lean mass, mainly in B, and a lower fat mass, that evolves with competition level. WI and LBMI are important for the morphological profile of young athletes. Representative sample size in males and direct anthropometric collections are required.
\end{abstract}

KEYWORDS: Acrobatic gymnastics; Anthropometry; Proportionality; Gender; Young athletes

\section{INTRODUCTION}

In a sport where athletes have different roles, it is common to find specific morphological characteristics, such as acrobatic gymnastics[1-4], where there are those who support (base- B) and those who are supported (top- T), particularly in women $[3,4]$. Female $\mathrm{T}$ are less tall, less heavy and have less fat mass than their base pairs, a difference that was not found for male pairs. The competitive level also shows anthropometric differences [4] With this study we intend a preliminary characterization of young Portuguese athletes of Acrobatic Gymnastics, of both genders; exploring potentialities and limitations of body composition formulas [2] and height and weight proportions between $\mathrm{T}$ and $\mathrm{B}$.
Quick Response Code:

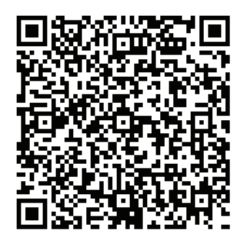

Address for correspondence: David Catela, Motricity Sciences PhD, Child Motor Development MSc, Life Quality Research Centre (CIEQV) and Research Centre of the Polytechnique Institute of Santarém (UIIPS), Complexo Andaluz, Portugal

Received: October 08, 2020 Published: December 29, 2020

How to cite this article: David Paulo Ramalheira C, Mafalda Nogueira S, Ana Paula de Lemos Teixeira e S. Body Composition and Proportionality of Base and Top in Acrobatic Gymnastics of Young Portuguese Athletes: Short Report. 2020 - 2(6) OAJBS.ID.000244. DOI: 10.38125/ OAJBS.000244 


\section{METHODS}

\section{Sample}

The sample is composed of 64 athletes $(11.73 \pm 2.76$ years of age, $148,77 \pm 16.56 \mathrm{~cm}$ in height, $40.49 \pm 12.59 \mathrm{~kg}$ in weight, $\mathrm{BMI}=$ $17.79 \pm 2.47, \mathrm{WI}=98.87 \pm 2.66,4.64 \pm 2.91$ years of age experience), $24 \mathrm{~T}, 7$ boys $(2 \mathrm{~T})$, from any acrobatic gymnastics modality.

\section{Procedure}

During 2018 national competitive events, with parents informed consent and athletes assent, through verbal information and based on last individual measurements made, weight and height were collected, jointly with time of practice in Acrobatic Gymnastics and best achievement at individual competitive level.

\section{Protocol}

Competitive level was defined as follows: i) without podium medals or $4^{\text {th }}$ regional place; ii) $3^{\text {rd }}$ or $2^{\text {nd }}$ regional places; iii) $1^{\text {st }}$ regional place till $1^{\text {st }}$ national place. Ordinal criteria for competitive level was validated by a panel of experts, composed by an Acrobatic Gymnastics' bachelor degree coach, a master degree professor with ISAK level two qualification, a doctoral degree professor in Motor Development, taking in consideration the national quality of Acrobatic Gymnastics in each competitive level.

Weight index $\left(\mathrm{WI}=\right.$ weight $/$ height $\left.^{3}\right)$, the lean body mass index $\left(\mathrm{LBMI}=\right.$ height $^{2} /$ weight$)$, and the body mass index (BMI = weight / height ${ }^{2}$ ) were estimated, and percentiles (P) 5 and 95 were calculated. Cutoff median value of LBMI is assumed to be 400 .

\section{Statistical Analysis}

Statistical analysis was made through IBM-SPSS, 23.0. ShapiroWilk test was used to verify normal distribution. To compare groups, were used Student test $(\mathrm{t})$, with homoscedasticity Levene test, and, Mann-Whitney U test (Z), with Monte Carlo correction, and effect size ( $\mathrm{r}$ ) and Mann-Whitney Glass rank-biserial correlation (rrb) were estimated for significant differences. One sample t test was used to compare LBMI of T and B with assumed cutoff value. Spearman correlation (rho) was used for analysis of association between variables. Probability error was set at 0.05 , bilateral.

\section{RESULTS}

Per role, the results revealed that the males did not differ from the females in any of the variables (B: age- $\mathrm{Z}(35,5)=0.0, p=1.0$; weight- - $\mathrm{Z}(35,5)=0.511, p=0.609$; height- $-\mathrm{Z}(35,5)=0.657, p$ $=0.511$; BMI- $-\mathrm{Z}(35,5)=0.593, p=0.553$; WI- $-\mathrm{Z}(35,5)=0.879$, $p=0.379$; LBMI- - Z(35,5) $=0.593, p=0.553$; time of practice- $\mathrm{Z}(35,5)=0.185, p=0.853$; $\mathrm{T}$ : age $\mathrm{Z}(22,2)=1.695, p=0.09$; weight $-\mathrm{Z}(22,2)=0.731, p=0.465$; height- $-\mathrm{Z}(22,2)=1.464, p=0.143$; BMI- - Z(22,2) = 1.044, $p=0.296$; WI- - Z(22,2) = 1.776, $p=0.076$; LBMI- - Z(35,5) = 1.044, $p=0.296$; time of practice- $-\mathrm{Z}(35,5)=$ $0.870, \mathrm{p}=0.384$ ).

Comparing $\mathrm{T}$ and $\mathrm{B}$, there were significant differences in height $(\mathrm{Z}(40,24)=5.179, p=0.0001, \mathrm{r}=0.65, \mathrm{rrb}=0.78)$ and weight $(Z(40,24)=5.623, p=0.0001, r=0.70, r r b=0.85)$; with the proportion of $\mathrm{T}$ for $\mathrm{B}$ for height being $87.44 \%$ (P5 = 91.61\%, P95 $=87.44 \%$ ), and for weight $62.83 \%$ (P5 $=67.60 \%$, P95 = 61.52\%).
Comparing $\mathrm{T}$ and $\mathrm{B}$, there were significant differences in BMI $(\mathrm{t}(62)=5.751)$, and LBMI $(\mathrm{t}(62)=5.865, p=0.0001)$, but not in WI $(\mathrm{t}(62)=0.632, p=0.530)$; with the proportion of $\mathrm{T}$ for $\mathrm{B}$ for BMI being 63.52\% (P5 = 66.69\%, P95 = 87.44\%), for WI 98.87\% (P5 = $102.24 \%$, P95 = 97.47\%), and for LBMI 117.74\% (P5 = 127.39\%, P95 = 104.33\%).

The average LBMI values of $\mathrm{B}(\mathrm{M}=536.94, \mathrm{SD}=67.54)$ and $\mathrm{T}(\mathrm{M}=632.44, \mathrm{SD}=54.64)$ are significantly higher than assumed cutoff value $(\mathrm{t}(39)=12.823, p=0.0001$, mean difference $=136.94$, CI $[115.34,158.54], \mathrm{t}(23)=20.841, p=0.0001$, mean difference = 232.44, CI [209.37, 255.51]; respectively). T were significantly younger $(\mathrm{M}=9.63, \mathrm{SD}=2.08)$ than $\mathrm{B}(\mathrm{M}=13.00, \mathrm{SD}=2.31)$ $(\mathrm{Z}(40,24)=4.762, \mathrm{p}=0.0001, \mathrm{r}=0.60, \mathrm{rrb}=0.71$ ) (cf., TaboadaIglesias et al. [2], and had significantly less time of practice $(\mathrm{M}=$ $3.67, \mathrm{SD}=2.14)$ than $\mathrm{B}(\mathrm{M}=5.23, \mathrm{SD}=3.17)(\mathrm{Z}(40,24)=4.762, p=$ $0.0001, r=0.60, \mathrm{rrb}=0.71$ ).

For all sample, there is a significant inverse association between competition level and WI (rho (64) $=-0.262, p=0.047$ ), with BMI with a non-significant direct association (rho (64) $=0.220, p=$ 0.081).

\section{DISCUSSION}

These young athletes already show a high lean mass, mainly B; with morphological characteristics similar to those found in other studies [3,4] and in age per role. However, contrary to [4] no gender differences were found; so, it would be interesting to verify if there is a tendency for a specific sport morphology per role, at least at these ages. WI and LBMI provided complementary information for the morphological profile [1,2] of these young acrobatic gymnasts. WI was also sensitive to level of competition impact and it is important to reconsider the suitability of using the BMI to characterize athletes. For young athletes, to establish an adequate proportion of physical characteristics among $\mathrm{B}$ and $\mathrm{T}$, percentile proportionality may offer complementary information.

To confirm the obtained data, it is necessary to make direct anthropometric collections; and, to obtain a sample size that is representative at the national level, particularly in males.

\section{ACKNOWLEDGEMENT}

Funding information: This study has a grant from the Portuguese Foundation for Science and Technology, I.P. (Number UIDP/04748/2020).

\section{REFERENCES}

1. Nevill AM, Holder RL (1995) Body mass index: a measure of fatness or leanness? In British Journal of Nutrition. 13.

2. Taboada IY, Gutiérrez SÁ, García RT, Vernetta SM (2019) Body proportionality in acrobatic gymnasts of different competitive categories. Science of Gymnastics Journal 11(1): 67-75.

3. Taboada IY, Gutiérrez SÁ, Vernetta SM (2016) Anthropometric profile of elite acrobatic gymnasts and prediction of role performance. The Journal of Sports Medicine and Physical Fitness 56(4): 433-442.

4. Taboada IY, Santana MV, Gutiérrez SÁ (2017) Anthropometric profile in different event categories of acrobatic gymnastics. Journal of Human Kinetics 57(1): 169-179. 